\title{
ЭТНОРЕГИОНАЛИСТИКА КАК НОВОЕ НАУЧНОЕ НАПРАВЛЕНИЕ ИССЛЕДОВАНИЙ В ГАГАУЗОВЕДЕНИИ (О НАУЧНОМ ТВОРЧЕСТВЕ МОЛДАВСКОГО ЭТНОЛОГА Е.Н. КВИЛИНКОВОЙ)*
}

\begin{abstract}
Статья посвящена рассмотрению новых подходов и методов исследования традиционной духовной культуры и этнической истории гагаузов, разработанных видным молдавским этнологом Е.Н. Квилинковой. Раскрывается значимость предложенного ею научного направления - этнорегионалистики и особенности использования термина «региональный». Своими исследованиями Е.Н. Квилинкова доказала, что реконструкция этнической истории дисперсно проживающего малочисленного народа возможна лишь путем изучения в ней общего и особенного через региональное. То есть ею обоснована необходимость компаративного исследования локальных этнических групп одного народа в разных регионах. в данной статье обобщен 30-летний опьт работы Е.Н. Квилинковой в Академии наук Молдовы и рассмотрены области духовной культуры гагаузов, изученные ею при помощи этнорегионального подхода. Анализ полученных результатов исследований, представленных в изданных ею научных статьях и монографиях, показал научную и практическую значимость такого научного направления как этнорегионалистика. Его использование в гагаузоведении еще более ценно, так как проблема этногенеза гагаузов (тюркоязычные и православные) до настоящего время остается одной из наиболее дискуссионных. в статье показано, что Е.Н. Квилинковой не только удалось изучить вопрос этногенеза гагаузов через культурогенез, но и вписать культуру гагаузов в нишу культур балканских христианских народов. В связи с этим отмечается вклад Е.Н. Квилинковой как ученого в гагаузоведение и в этнологическую науку в целом.
\end{abstract}

Ключевые слова: Е.Н. Квилинкова, этнология, этнорегионалистика, методbl, гагаузоведение, этническая история, этногенез

Для цитирования: Квилинкова Е.Н. Этнорегионалистика как новое научное направление исследований в гагаузоведении // Вестник антропологии, 2021. № 4. С.309-324

Имя Квилинковой Елизаветы Николаевны - доктора исторических наук, доцента, молдавского этнолога (гагаузского происхождения) с 30-летним научным стажем в Академии наук Молдовы хорошо известно в академических кругах, а также специалистам за пределами страны. Она - выпускница исторического факультета

Сакович Василий Андреевич - доктор политических наук, профессор, Академия управления при Президенте Республики Беларусь (Республика Беларусь, г. Минск, ул. К. Маркса, 24). Эл. почта: 113vs@mail.ru 
Московского Государственного университета им. М.В. Ломоносова (1991). в 2002 г. защитила диссертацию на соискание ученой степени кандидата исторических наук в Российской академии наук (в Институте им. Н.Н. Миклухо-Маклая), а в 2008 г. диссертацию на соискание ученой степени доктора хабилитат исторических наук в Академии наук Республики Молдова (Институт истории, государства и права).

Перечислю основные исследованные ею области традиционной духовной культуры гагаузов, по которым у нее изданы объемные научные монографии: календарная и семейная обрядность, соционормативная культура, терминология родства, народная медицина, народная метеорология, песенный и сакральный фольклор, апокрифическое наследие, православная паломническая традиция, религиозная и языковая идентичности, обряд курбан, культ волка, национальные символы и символика и мн. др. Уже из названий исследованных ею областей видно, что она изучила не только всю традиционную духовную культуру гагаузов, но и отдельные направления этносоциальной психологии - феномен национальной символики и символизма, паломничество к Гробу Господню как религиозный и социокультурный феномен и др.

Даже беглое знакомство с гагаузской библиографией показывает, что Е.Н. Квилинкова одна из самых продуктивных авторов в гагаузоведении как по количеству изданных работ, так и по охваченным ею исследовательским областям. Впечатляет объем изданных ею научных трудов - около 400 работ: из них более 300 научных публикаций, из которых 23 монографии (13 - индивидуальных монографий, 1 фольклорный сборник и 1 научно-методическое пособие), и более 80 - научно-популярных статей. Она активно участвует в международных научных конференциях, симпозиумах и конгрессах. Ее труды хорошо известны за рубежом. И более всего их опубликовано в России. Не лишним будет упомянуть и о том, что кроме Академии наук Молдовы изданные ею индивидуальные монографии выходили также под грифами известных в мире научных заведений других стран: Института востоковедения Российской академии наук, Академии наук Беларуси, Академии наук Республики Татарстан, Софийского университета, Юго-Западного университета (Благоевград, Болгария) и др.

В данной статье мне бы хотелось не только назвать те области гагаузоведения, в которые Е.Н. Квилинкова внесла огромный вклад (многие из них ей пришлось изучать практически с нуля), но и рассмотреть эффективность использованных ею методов исследования, а также остановиться на содержании и значимости разработанного ею и апробированного на практике нового научного направления - этнорегионалистики. Его применение в гагаузоведении еще более ценно на фоне понимания того, что проблема этногенеза гагаузов (тюркоязычные и православные) до настоящего время остается одной из наиболее дискуссионных.

В чем же специфика такого научного направления как «этнорегионалистика»? Е.Н. Квилинкова делает акцент на изучении этнической истории гагаузов через призму этнокультурной идентичности и региональных особенностей, характерных для различных групп этого народа. Понятие «регион» рассматривается ею не в чисто географическом, а в регионально-этнокультурном значении. Е.Н. Квилинкова рассматривает термин регион (региональный) в связи с территорией (регионом) компактного расселения конкретно изучаемых групп одного народа, проживающих отдельно от основного этнического ядра в пределах других государств. То есть исследуется его локальные этнические группы в разных регионах через призму сохранности этнической идентичности и результатов межэтнического взаимодействия. 
Иными словами, если с позиций регионалистики становится возможной реконструкция древнейшей этнической истории определенного ареала / региона, то этнорегионалистика, как научное направление разрабатываемое Е.Н. Квилинковой, позволяет реконструировать этническую историю дисперсно проживающего малочисленного народа путем изучения в ней общего и особенного через региональное. Для этого различные области традиционной духовной культуры и самосознание, характерные для представителей этнического ядра - гагаузов Молдовы, анализируются Е.Н. Квилинковой в сравнении с региональными особенностями, свойственными его «внешним» группам - гагаузам Болгарии, Греции, Украины и др., живущим вне пределов основного этнического образования. Как следует из проведенных ею исследований, в силу исторических причин, природно-географических условий и этнокультурной среды этих регионов (государств) для проживающих там этнических групп гагаузов характерны существенные отличия, поскольку они вобрали в себя свойственную этим территориям культурно-региональную специфику.

Изучение этнических групп в синхронном и диахронном срезе важно, поскольку позволяет реконструировать этническую историю, изучать вопросы культурогенеза и этногенеза. Это является значимым еще и потому, что сложные социальные и этнические процессы, протекающие в современном обществе, ведут к росту национального самосознания, пробуждая историческую память народов. Но нередко это приводит к созданию этноисторических мифов, ничего общего не имеющего с историей.

Значимость такого направления как этнорегионалистика для гагаузоведения более чем актуально, так как в гагаузской истории и культуре сохраняется много белых пятен, да и происхождение этого народа до настоящего времени остается загадкой. Очевидно, что решение столь сложных задач невозможно без привлечения данных различных гуманитарных дисциплин, анализ которых должен проводиться на более высоком теоретическом уровне, что и осуществила в своих работах Е.Н. Квилинкова.

Исследования Е.Н. Квилинковой основываются на этнорегиональном и междисциплинарном подходах. Она оперирует обобщенными данными, опираясь на результаты собственных полевых исследований каждой из областей традиционной духовной культуры гагаузов и их самосознания. Более высокий уровень обобщения и анализа был проведен Е.Н. Квилинковой при выявлении региональных особенностей и результатов адаптации указанных групп гагаузов в местную этнокультурную среду. Для этого в качестве объекта сравнительно-сопоставительного изучения она взяла наиболее близкие по культурной дистанции народы (проживающие по соседству в тех же регионах - болгар, греков; молдаван, румын, украинцев и др.), а также те, которые рассматриваются гагаузоведами как генетические родственные - тюркоязычные народы. Из полученных ею данных следует, что традиционная духовная культура гагаузов во многом схожа с болгарской, в то время как тюркский пласт представлен в ней незначительно. Все свои выводы она обстоятельно и научно аргументировала на обширном полевом материале.

Опубликованные Е.Н. Квилинковой результаты исследований вызвали в среде гагаузоведов бурные дискуссии, которые у оппонентов не всегда оставались в рамках научного поля. Это можно объяснить тем, что приведенные ею новые данные, введенные в научный оборот, обнажили слабые стороны существующей тюркской теории о происхождении гагаузов, потребовали пересмотра данных по этногенезу и этнической истории гагаузов, а также сделали невозможным игнорирование факта 
значительного сходства гагаузской традиционной культуры с болгарской. Еще большую остроту данный вопрос приобрел после того, как Е.Н. Квилинкова опубликовала новые сведения по особенностям языковой и этнической идентификации у разных групп гагаузов (Квилинкова 2007: 375-395). Углубившись в работу с фондами Национального архива Молдовы, она привела довольно много неопубликованных документов, подтверждающих использование гагаузами принципа двойной идентификации (в том числе бессарабскими гагаузами - в прошлом), а также раскрывающих процесс мобилизации этнической идентичности и становление этнонима «гагауз» и глоттонима «гагаузский язык» (Квилинкова 2013: 43-77, 267-330).

Е.Н. Квилинкова - это ученый с принципиальной и непредвзятой позицией, которая считает важным разрешать проблему, а не завуалировать ее. Таким образом, умело применяя этнорегиональный и междисциплинарный подходы, а также многоуровневый анализ всех имеющихся данных она представила научной общественности новые знания об отличительных признаках и характерных чертах гагаузской традиционной обрядности, фольклора, терминологии, об особенностях этнической и языковой идентификации, о сложностях этнокультурной идентификации гагаузов в современный период и т.д.

Как можно судить по опубликованным ею работам разработку нового научного направления с целью изучения генезиса этнической культуры гагаузов Елизавета Николаевна приступила в начале 2000-х гг. Для того, чтобы выявить этническую специфику в той или иной области культуры, рассмотрения только одной группы гагаузов Молдовы оказалось явно недостаточно, так как после переселения с Балкан на территорию Бессарабии они оказалась в другом природно-географическом и этническом окружении. Для выявления же ядра традиционной духовной культуры гагаузов, его этнокультурных маркеров и кода, необходимо было изучить и проанализировать особенности процесса адаптации и аккультурации у других групп гагаузов, проживающих в других регионах.

Таким образом, Е.Н. Квилинкова пришла к выводу о том, что широты и глубины исследования можно добиться не только привлекая данные по различным гуманитарным дисциплинам, но и при помощи сбора материала по другим группам гагаузов и его историко-сравнительного анализа, а также путем учета степени сохранности или утраты гагаузами тех или иных обрядов, результатов этнокультурного взаимодействия и т.д. Изучение областей традиционной духовной культуры у различных групп гагаузов осуществлялось ею в синхронной и диахронной плоскости. в связи с проведенными Елизаветой Николаевной масштабными и глубокими исследованиями считаем необходимым несколько подробнее остановиться на особенностях использованных ею подходов и полученных результатах.

Началом апробации этнорегионального подхода является работа «Гагаузы Молдовы и Болгарии (Сравнительное исследование календарной обрядности, терминов родства и фольклора)» (Квилинкова 2005). Подход к научному обоснованию нового направления - этнорегионалистики был осуществлен ей в монографии «Традиционная духовная культура гагаузов: этнорегиональные особенности» (Квилинкова 2007). Эта работа представляет собой первый в гагаузоведении опыт исследования, на основании которого автор, умело оперируя данными различных дисциплин и разными методами, пришел к принципиально новым выводам. 
Для того чтобы вычленить этнокультурные, региональные и локальные особенности гагаузов определенного региона она подвергла сравнительному анализу календарные обычаи, обряды, песенный фольклор, термины родства не только у всех исследуемых групп гагаузов, но и у иноэтничного населения региона их проживания. Весь собранный материал проходил множественную фильтрацию. Анализ всех факторов, рассмотренных в совокупности, позволил ей охарактеризовать особенности каждой из групп гагаузов через изучаемое региональное пространство и через этническую общность. Именно эти критерии заставили ее как профессионального этнолога с большим опытом, чутьем и проницательностью исследовать характерные для них явления через систему, отражающую региональные особенности. Отсюда у нее родилось понимание важности и необходимости изучать генезис гагаузской народной культуры через воздействие природно-географических, экономических и этносоциальных факторов на каждую из региональных групп.

Этнорегионалистика как уже апробированное научное направление, со свойственными ему методами и подходами (междисциплинарный, комплексный и др.), стало применяться Елизаветой Николаевной во всех последующих исследованиях. Пример сочетания этнорегионального подхода с привлечением данных различных дисциплин - этнологии, фольклористики, лингвистики, психологии и религиоведения демонстрируют следующие монографии Е.Н. Квилинковой: «Заговоры, магия и обереги в народной медицине гагаузов» (Квилинкова 2010), «Гагаузский песенный фольклор “Грамматика жизни”» (Квилинкова 2011), «Апокрифы в зеркале народной культуры гагаузов» (Квилинкова 2012), «Православие - стержень гагаузской этничности» (Квилинкова 2013), «Курбан у гагаузов (Архаическая современность)» (Квилинкова 2015), «Гагаузы в этнокультурном пространстве Молдовы (народная культура и этническое самосознание гагаузов сквозь призму связи времен)» (Квилинкова 2016).

Результатом изучения Е.Н. Квилинковой каждой новой области традиционной духовной культуры гагаузов стало установление их этнического ядра, выявление последовательности исторических напластований в народной культуре и региональных этнокультурных компонентов: южнославянского, тюркского, восточнороманского и восточнославянского. Каждое из монографических исследований, помимо ценных приложений с полевыми материалами, включает большие разделы, посвященные изучению векторов этнокультурных параллелей. Например, в работе «Заговоры, магия и обереги в народной медицине гагаузов» сакральный фольклор и народные способы лечения изучены в контексте балканской традиции (Квилинкова 2010: 196-246).

В монографии «Гагаузский песенный фольклор - “Грамматика жизни”» данный вид народного творчества исследуется ею как историко-этнографический источник через призму традиционной материальной и духовной культуры (Квилинкова 2011). Этнографические факты в народных песнях сравниваются и сопоставляются с этнографической действительностью. Автор в синхронном и диахронном срезе рассматривает общие элементы и региональные особенности, характерные для песенного фольклора гагаузов Молдовы, Болгарии, Греции и Украины, степень его сохранности у каждой из групп и результаты инокультурных влияний в данной области культуры. Им анализируется также такой ранее совершенно неисследованный гагаузоведами пласт фольклора как духовные стихи. При выявлении этноспецифических черт гагаузской культуры Е.Н. Квилинкова объективно показывает представленность в ней различных этнических компонентов, том числе болгарского и тюркского. Одной из 
установленных автором характерных черт народного песенного творчества гагаузов, объединяющей ее с тюркскими народами, является «отсутствие традиции хорового пения; почти все гагаузские песни одноголосны» (Квилинкова 2011: 345-347).

В монографии «Апокрифы в зеркале народной культуры гагаузов» религиозная рукописная традиция, представленная письменными памятниками апокрифической литературы, рассматривается ею в контексте православной религиозной идентичности, а также через призму этнокультурных контактов и влияний. Ею выявлены орфографические и стилистические особенности гагаузских рукописных сборников, проанализированы причины сложности перевода апокрифических молитв на гагаузский язык, рассмотрена представленность в них молдавской лексики (Квилинкова 2012: 268-365). О данном монографическом исследовании Елизаветы Николаевны, являющимся вкладом не только в балканистику, но и в европейскую культурологию, писали болгарские ученые (Драгова 2012: 360-361).

В монографии «Православие - стержень гагаузской этничности» Е.Н. Квилинкова проанализировала значимость православной идентичности как одного из основополагающих факторов этнического самосознания гагаузов. При анализе православия как важной составляющей гагаузской ментальности, большое внимание уделяется вопросу о начале издания религиозных книг на гагаузском языке, а также роли гагаузского языка и религиозной литературы в процессе этноконсолидации (Квилинкова 2013: 302-451). в работе проанализировано влияние исторических условий на изменение динамики соотношения идентичностей - конфессиональной и языковой. Полученные результаты рассмотрены через призму механизма «народного самосохранения» и этнической мобилизации. в результате проведенного исследования Е.Н. Квилинкова сформулировала основные признаки, составляющие ядро гагаузской этничности: христианство (в форме православия) и тюркоязычность.

Продолжением исследования в области православной религиозности является монография Е.Н. Квилинковой «Хаджылык у гагаузов как религиозный и этнокультурный феномен: от прошлого к настоящему» (Квилинкова 2017). в ней паломничество (в частности, к Гробу Господню) исследовано как в историческом контексте, так и в связи с современной паломнической традицией, сквозь связь времен и поколений. Автором осуществлен историко-культурный анализ указанного феномена, проанализировано имеющиеся сходство гагаузской паломнической традиции с болгарской, а также выявлены ее характерные черты, отличающие гагаузский хаджылык от мусульманского хаджа. в данной работе традиция православного паломничества у гагаузов изучена на стыке истории, этнологии, религиоведения, культурологии, фольклористики, социологии и психологии.

В монографии «Курбан у гагаузов (Архаическая современность)» Е.Н. Квилинкова предприняла удачную попытку культурологического анализа обряда курбан, являющегося важной частью института жертвоприношения у гагаузов. Он изучен ею через призму ритуала, символа и культурного кода. Автору удалось показать, что в мировоззрении и традиционной культуре гагаузов тесно переплелись православная религиозность с реликтами язычества, балканская культурная компонента с тюркской составляющей (Квилинкова 2015). Все эти проявления демонстрируют особенность гагаузской этнокультурной идентичности, этнической истории и менталитета.

Комплексным и междисциплинарным исследованием, представляющим собой результат 25-летней научно-исследовательской деятельности Е.Н. Квилинковой, яв- 
ляется монография «Гагаузы в этнокультурном пространстве Молдовы (народная культура и этническое самосознание гагаузов сквозь призму связи времен)» (Квилинкова 2016). в ней Елизавета Николаевна реконструировала различные пласты их этнической культуры, выявила степень сохранности народной культурой этнических черт. Особенностью данного исследования является то, что в ней впервые в гагаузоведении комплексно изучен феномен традиционной духовной культуры гагаузов, выявлены ее основные компоненты и этнокультурные маркеры, проанализированы особенности в области этнической и языковой идентификаций, характерные для различных групп гагаузов. Путем изучения символического кода, заложенного в пословицах и поговорках, а также анализа данных проведенного соцопроса, автору удалось выделить основные черты гагаузского национального характера (Квилинкова 2016: 169-184). Если говорить в целом, то в данном исследовании Елизавета Николаевна сумела рассмотреть вопрос этногенеза гагаузов через культурогенез.

В монографии «Культ волка у гагаузов сквозь призму этнокультурных символов» Е.Н. Квилинкова вышла на совершенно новый уровень исследования и теоретического анализа (Квилинкова 2014). Дело в том, что волк является одним из важных символов, через который часть гагаузской национальной элиты стремится «усилить» свои тюркские корни, показать генетическую общность с тюркскими народами и таким образом обосновать этногенез гагаузов. Это исследование Елизаветы Николаевны можно охарактеризовать как обстоятельный научный ответ на острый и чрезвычайно дискуссионный вопрос о действительных корнях и содержании образа волка и Волчьих праздников у гагаузов.

Данная работа является примером изучения проблемы в духе этнорегионалисти$\kappa u$. в ней приведены разные виды источников, осуществлен анализ разнообразных явлений на различных теоретических уровнях, обосновано новое знание о характере гагаузской этнической культуры и этнической истории. Для этого автор глубоко исследовал формы культа волка, мифические представления и традиционную обрядность у всех групп гагаузов в сравнении с балканскими и тюркскими народами (Квилинкова 2014: 68-123, 172-215).

Ввиду особой актуальности образа волка в современной этнополитической истории гагаузов от Елизаветы Николаевны, как от исследователя, потребовалось проанализировать элементы культа волка у гагаузов не только как важной составляющей системы традиционного мировоззрения, но и как этнокультурный символ, включенный в национальную символику. Ею было выявлено, что традиционное содержание образа волка и Волчьих праздников принципиально расходится со смыслом, который стремятся вложить в этот образ часть гагаузской политической элиты, творческой интеллигенции и ученых (Квилинкова 2014: 324-345). Осуществленный в работе анализ позволил автору раскрыть значение данного этнокультурного символа как механизма культурной памяти и как мощного ресурса этнической мобилизации в современный период.

Расширение диапазона междисциплинарности характеризует одну из последних монографий Е.Н. Квилинковой - «Соционормативная культура гагаузов: традиции и трансформации» (Квилинкова 2020а). в ней соционормативная культура исследована через призму «культуры повседневности» как способ жизнедеятельности и как важная составляющая культурной традиции. На основе полевого (этнографического и фольклорного), архивного и историографического материалов автор рассмотрел тра- 
диционные модели поведения и методы воспитания в семье, способы предотвращения конфликтов и др. Особое внимание он уделил анализу гагаузской терминологии соционормативной культуры. Важное место в этой работе занимают вопросы изучения ментальности гагаузов как формы общественного сознания и психологии, воплощенной в языке и других знаковых системах, традиционным формам приветствия как значимой части гагаузского этноэтикета, а также анализу смысла традиционного дарообмена как регулятора социальных взаимоотношений между родственными группами. Через пословицы и поговорки автор раскрыл этику, мораль и социальные нормы гагаузов.

Характеризуя в целом подход Е.Н. Квилинковой к изучению традиционной духовной культуры гагаузов, отметим, что она исследована ею через призму гагаузского этнокультурного кода и как способ сохранения и межпоколенной трансляции основных признаков этнической культуры. Научная значимость ее работ состоит в том, что в них автор рассмотрел различные уровни этнокультурной идентичности гагаузов: этническую, религиозную, региональную. Принципиальный, на наш взгляд является сделанный ею научный вывод о том, что наряду с языком (тюркоязычные) у гагаузов важную роль в этнической идентификации играет религиозная идентичность. Благодаря введению в научный оборот полевых и архивных источников ей удалось рассмотреть формы проявления у них религиозной идентичности, выявить место православной идентичности в этнокультурном коде гагаузов, что, несомненно, является весомым вкладом в изучение феномена гагаузкой этнической идентичности.

Что касается научной деятельности Елизаветы Николаевны отметим, что все ее работы отличает комплексный, междисциплинарный и этнорегиональный подходы. в своих исследованиях она широко привлекает и анализирует источники по различным областям гуманитарных наук. в них впервые изучены феномен традиционной духовной культуры гагаузов, этапы формирования самосознания гагаузов, маркеры этнической идентичности, актуализировавшиеся в 80-е - 90-е гг. ХХ в. при создании гагаузской государственности, а также в современный период в связи с необходимостью ее сохранения и мн. др. Путем творческого синтеза данных различных дисциплин и сочетания разных методов исследования ею были получены новые данные об этнической культуре гагаузов, о свойственных отдельным группам этого народа ряда региональных признаков и характеристик, об адаптивных возможностях их культурного потенциала и др.

Хочется подчеркнуть еще одну важную черту Е.Н. Квилинковой, о которой говорят все ее коллеги. Она - «полевик» от Бога. Все ее научные труды целиком основываются на собранном ею лично богатом полевом этнографическом и фольклорном материале, собиравшемся на протяжении 30 лет, а также на введенных в научный оборот архивных источниках. Поэтому если многим этнологам, изучающим другие народы, повезло, поскольку им приходилось решать задачу «освоения багажа», накопленного как предыдущими исследователями - этнографами, так и представителями других гуманитарных наук, то Е.Н. Квилинковой пришлось самой нарабатывать всю базу данных и лишь затем переходить на более высокий уровень теоретических обобщений и трансдисциплинарности.

На особую значимость полевых данных для изучения истории и культуры гагаузов обращал внимание известный российский этнолог и этносоциолог, заместитель директора института этнологии и антропологии Российской академии наук, профессор М.Н. Губогло. в одной из рецензий, написанных на монографию Е.Н. Квилин- 
ковой, он особо подчеркивал ее уникальную способность находить нужных информаторов, раскрывать их и добывать у них ценный полевой материал (Губогло 2010: 14). Несмотря на то, что по некоторым научным вопросам М.Н. Губогло остро дискутировал с Е.Н. Квилинковой, тем не менее он поддерживал ее положительным рецензиями как на диссертационные работы, так и на издававшиеся монографии.

Особое внимание М.Н. Губогло обращал на актуальность использования гагаузоведами трансдисциплинарного подхода, приводя в пример работы указанного автора: «Е.Н. Квилинкова исходит из широкого определения фольклора, что позволяет не оставлять без внимания обширные области народных представлений, народных знаний и повседневного поведения, которые как раз и связывают фольклор с другими элементами культуры. Более того, рассматривая обрядовые поэтические фольклорные тексты в контексте с традиционной обрядностью, так же, как и заговоры в комплексе с магическими обрядовыми действиями, автору удается показать неразрывность структуры текста от функции, от действий и представлений, породивших этот текст. Словом, работу Е.Н. Квилинковой отличает отсутствие одностороннего понимания текста и фольклора, что порой встречается в публикациях некоторых современных гагаузских фольклористов и этнологов, интерпретирующих фольклор как исключительно вербальное народное творчество и ограничивающих его рядом особо выделенных жанров» (Губогло, 2011б: 8).

Ценность такого рода работ Михаил Николаевич видел в расширении предметной области исследования и в укреплении связи этнографии с фольклористикой. «В новой книге Е.Н. Квилинковой явления и факты вербальной духовной культуры, относящиеся к сфере фольклора, исследуются во всем их многообразии. Междисциплинарный подход, в том числе включение в сферу исследования малоизвестных ранее материалов, почерпнутых из ,запасников” традиционной культуры, а также применение апробированной методики позволяет установить не только взаимосвязь песенного фольклора с традиционной обрядностью, но и достоверность содержащихся в тексте данных, осуществлять изучение песенного фольклора с целью установления в нем разнообразных последовательно возникавших хронологических напластований. Все это позволило автору значительно расширить предметную область исследования и объективно способствовало укреплению связи фольклористики с этнографией. Сегодня стало возможным лучше видеть этнологические аспекты песенного творчества гагаузов, в том числе через призму сравнительно-исторической лексикологии и через призму филологии» (Губогло 2011б: 15).

Надо сказать, что именно в разработанном и применяемом Е.Н. Квилинковой на практике новом научном направлении - этнорегионалистике, в изучении ею этнорегиональных особенностей традиционной духовной культуры гагаузов и выявлении этнического кода гагаузов профессор видел одну из возможностей изучения истории гагаузского народа: «Мы, читатели, уже привыкли к тому, что в ряде своих публикаций Е.Н. Квилинкова раскрывает тайну, ритуальные технологии и обрядовые практики традиционной культуры гагаузов. Впечатляет, в частности, ее подвижнический труд, посвященный этнорегиональным особенностям традиционной духовной культуры гагаузского народа. Неистощимая страсть к полевой работе и высокий профессионализм процедурных средств, используемых ею для накопления, систематизации и аналитического осмысления эмпирического материала, представляют несомненную ценность. Ее тексты не только являются важным вкладом в описание и в распознание особенностей 
традиционной культуры, но и проливают дополнительный свет как на непрочитанные страницы истории гагаузского народа, так и на его соционормативную культуру, если воспринимать эту культуру как своеобразную „грамматику жизни”» (Губогло 2010: 9).

Об осуществленных Е.Н. Квилинковой глубоких исследованиях по истории и культуре гагаузского народа не раз писали именитые молдавские и зарубежные ученые: президент Академии наук Молдовы, академик - Г.Г. Дука; академик Академии наук Молдовы - Г.Е. Руснак; член-корреспондент Академии наук Молдовы - В.И. Царанов; доктор, профессор Славянского университета Республики Молдова - И.А. Ионова; доктор, профессор Тараклийского университета Республики Молдова - Н.Н. Червенков (Республика Молдова); заместитель директора института этнологии и антропологии Российской академии наук, доктор наук, профессор М.Н. Губогло; заведующая отделом этнологии Института истории Академии наук Республики Татарстан, доктор наук - Г.Ф. Габдрахманова, заведующий отделом истории татаро-булгарской цивилизации Института истории Академии наук Республики Татарстан - А.А. Бурханов; профессор Юго-Западного университета (Благоевград, Болгария), доктор наук - Н.Н. Драгова, профессор Института балканистики Академии наук Болгарии, доктор наук - В. Трайков, доцент Велико-Тырновского Университета, доктор наук - Н. Колев, директор Института этнографии с музеем Академии Болгарии, доктор наук, доцент - П. Христов и др.

Надо сказать, что за 30-летний период исследовательской работы Елизавета Николаевна наработала большой теоретический и практический опыт, который она представила в виде научно-методического пособия «Методика и практика этнологических исследований» (Квилинкова 2020б). в нем раскрываются методы и методика разработанного и практически примененного ею в гагаузоведении нового научного направления, именуемого этнорегионалистика. Автор делится своим опытом изучения этнокультурных процессов и результатов межэтнического взаимодействия в области традиционной обрядности, через которые рассматривает культурно-исторический контекст жизнедеятельности отдельно взятой этнической общности (проблема этногенеза которой не разрешена) и характер ее взаимоотношений с соседними народами.

В настоящем пособии автор не только раскрывает использованные им методы и методики этнологических исследований традиционной духовной культуры гагаузов, осуществленных в междисциплинарном ключе, и определяет проблемно-тематические направления научного «поля», но и предпринимает попытку анализа через автоэтнографию собственного опыта полевой работы. Подчеркнем, что упомянутое научно-методическое пособие - это первая такая работа в гагаузоведении. Предложенная автором пособия методика является универсальной, поскольку разработанная им программа-вопросник может применяться для углубленного изучения календарной обрядности не только у различных групп гагаузов, но и у других этносов.

Подводя итог вышесказанному, отметим, что исследования Е.Н. Квилинковой базируются на самостоятельно выработанных научных методах и методических подходах, на лично собранном полевом материале. Традиционная духовная культура гагаузов исследована ею во временном и пространственном разрезах, через призму трех форм идентичности - этнической, конфессиональной и социально-бытовой. Благодаря использованию этнорегионального подхода и историко-сравнительному методу ею изучены также особенности в самосознании и культуре четырех групп гагаузов - Молдовы, Украины, Болгарии и Греции. 
Несомненно, что новое научное направление - этнорегионалистика (Квилинкова 2021: 352-355) и разработанный ею этнорегиональный метод будут востребованы другими учеными, изучающими этническую историю малочисленных и дисперно проживающих народов. Накопленная Елизаветой Николаевной оригинальная и фундаментальная полевая база по традиционной духовной культуре гагаузов, а также выявленные архивные источники по проблеме, введенные в научный оборот, послужат основой для дальнейших сравнительных изысканий по этнической истории и культуре гагаузов.

Вкладом Е.Н. Квилинковой в гагаузоведение и в этнологическую науку является то, что на основании историко-сравнительного изучения традиционной духовной культуры и анализа полученных данных, ею были обоснованы основополагающие положения в области гагаузской этнической истории, а именно: гагаузы - это этническая общность балканского происхождения, со свойственным христианским народам данного региона культурно-мировоззренческим кодом, в основе этнокультурной идентичности которых лежат две составляющие - тюркскость и православие; этническая специфика традиционной культуры гагаузов сформировалась на Балканах, до их переселения в Бессарабию; «Волчьи праздники» и культ волка у гагаузов по форме и содержанию представляют собой общебалканское явление, так как он в равной степени характерен и народам Балканского региона, у которых основа обрядности аналогичная; культ волка у гагаузов принципиально отличается от культа волка, характерного для тюркских народов; и др. (Квилинкова 2005: 92; 2014: 214-215).

Кроме того, Елизаветой Николаевной были выявлены этнические маркеры традиционной духовной культуры гагаузов. Несмотря на то, что данная задача была очень непростой ввиду значительное сходства гагаузской и болгарской традиционных культур, она с нею успешно справилась. в ее работах находим и научное объяснение имеющемуся сходству. в качестве основных факторов ею перечислены следующие: длительное совместное проживание в одинаковых природно-географических условиях, общая историческая судьба, единая религиозная принадлежность (православие), а также вхождение части болгарского элемента в гагаузский этнос (Квилинкова 2016: 102).

Сделанные Е.Н. Квилинковой выводы в монографиях не только раскрывают характер историко-культурных процессов у гагаузов, но и объясняют их этническую составляющую, что представляет особый научный интерес для исследователей-балканистов и тюркологов. Таким образом, в результате изучения этнической истории гагаузов Елизаветой Николаевной было определено место традиционной духовной культуры гагаузов среди других европейских культур, выявлено сходство гагаузской традиционной обрядности с обрядностью народов Балкано-Дунайского региона, обоснованы полученные этногенетические данные. Все это позволило ей вписать культуру гагаузов в нишу культур балканских христианских народов.

Проанализировав процессы социальной и исторической динамики этнической культуры гагаузов (культурогенез), а также особенности их самосознания на разных этапах этнической истории и сделав соответствующие выводы Е.Н. Квилинкова тем самым внесла в область гагаузоведения новое знание не только об этнической культуре гагаузов, но и об их происхождении. И это не случайно. Ученые подчеркивают, что «этногенез и этническая история не относятся ни к исторической географии, ни к регионалистике, но из всех наук проблемы этногенеза ближе всего регионалистике и этнографии». Таким образом, среди комплексных междисциплинарных исследо- 
ваний как самостоятельные направления ученые выделяют следующие: этногенез и этническую историю, историческую географию и регионалистику (Толстой 1995: 41-60; Герд 2013: 112-113, 115).

Использованные подходы и методы позволили Е.Н. Квилинковой объяснить процессы этнокультурного развития гагаузов как в рамках отдельных регионов, так и в этническом контексте. Ее работы представляют интерес для широкого круга специалистов - этнологов, историков, фольклористов, этнолингвистов, этносоциологов, этнопсихологов, антропологов, культурологов, так как в работе раскрывается сам механизм этнокультурного взаимодействия.

Внесенный ею научный вклад в изучение гагаузов, а также в разработку новых методов исследования их истории и культуры позволяет утверждать, что Е.Н. Квилинкова является не только видным молдавским этнологом, но и славной дочерью своего народа, которая приложила все свои усилия и знания для того, чтобы малочисленный, но уникальный по своим традициям и культуре гагаузский народ занял достойное место среди других народов и культур.

Нельзя не сказать и об учителях, которым Елизавета Николаевна высказывала свою признательность и благодарность. Так, одну из первых своих монографий «Гагаузы Молдовы и Болгарии» (Квилинкова 2005) она посвятила памяти профессора В.С. Зеленчука - научного руководителя по кандидатской диссертации. Тесные научные отношения связывали ее с известным российским этнологом, профессором М.Н. Губогло. От него она многому научилась - научным подходам, широте видения проблемы и др. в этом смысле ее можно считать его ученицей. в статье, посвященной памяти М.Н. Губогло (2020), Елизавета Николаевна высказала ему слова признательности, за поддержку, оказанную ей и другим молодым гагаузским этнологам, в организации защиты кандидатских диссертаций в Институте им. Н.Н. Миклухо-Маклая. Она с благодарностью вспоминает тот опыт работы и возможность общения со своим земляком, который у нее был.

Е.Н. Квилинкова являлась своего рода связующим звеном между М.Н. Губогло и молдавскими учеными, помогая ему организовать ученых для участия в коллективной монографии «Молдаване» (2010), а также в российско-молдавских симпозиумах. в другой коллективной монографии «Гагаузы» (2011), также вышедшей в серии «Народы и культуры», М.Н. Губогло и Е.Н. Квилинкова являются ответственными редакторами. При научном участии и организационном содействии Елизаветы Николаевны был реализован ряд других его научных проектов: коллективная монография «Гагаузы в мире» и «Мир гагаузов» в 2-х томах (2012), сборники по материалам российско-молдавских симпозиумов «Курсом развивающейся Молдовы» и др.

30 лет в науке - это, можно сказать, середина пути научной деятельности. Е.Н. Квилинкова отмечена рядом дипломов Академии наук Молдовы, благодарностей и медалями Гагауз Ери. Дипломами: «За продвижение результатов научных исследований на международной арене и в связи с празднованием Всемирного дня науки» (2010); «За высокие результаты в научной деятельности и в связи с празднованием 70-летия создания первого научно-исследовательского института и 55-летия со дня основания Академии наук Молдовы» (2016); «За выдающиеся успехи в исследовании и сохранении культурного наследия и в связи с празднованием 25-летней годовщины создания гагаузоведения в Академии наук Молдовы» (2012); «За активное участие в научной деятельности Республики Молдова и значимый вклад в продвижении тра- 
диционных культурных ценностей гагаузов» (2016). Благодарностью Управления культуры Гагаузии за исследование культуры и традиций гагаузского народа и их пропаганду среди работников культуры Гагауз Ери (2001). Медалью АТО Гагаузии «Gagauz Yeri - 15 YIL» (2009); Медалью АТО Гагаузии «Gagauz Yeri» (2012).

С июля 2020 г. Елизавета Николаевна по семейным обстоятельствам переехала в Беларусь, где трудится в Национальной академии наук Беларуси в Институте искусствоведения, этнографии и фольклора им. К. Крапивы, в связи с чем тематика ее научной деятельности существенно расширилась. Уже в этом 2021 г. она, совместно с автором данной статьи, издала монографию «Белорусы в Молдове и Молдова в белорусах» (Квилинкова, Сакович 2021). Кроме того, Елизавета Николаевна начала исследование по татарам Беларуси. Несомненно, что ей пригодится наработанный ранее опыт изучения тюркоязычного этноса. Помимо этого, она занимается изучением молдавской диаспоры в Беларуси, чем, видимо, хочет отдать долг свой Родине. Ну и поскольку родилась она в Гагаузии (девичья фамилия Касым), то у нее сохраняется не только любовь к своему народу, но и исследовательский интерес. Она продолжает его изучать, где бы ни находилась. Несмотря на то, в Беларуси гагаузов очень мало, тем не менее она уже собирает по ним полевой материал, который планирует представить в следующей своей монографии.

\section{Научная литература}

Герд А.С. Историческая география и регионалистика: взаимоотношение в процессе изучения историко-культурных зон // Псковский регионологический журнал. Псков, 2013. С. 107-116. https://cyberleninka.ru/article/n/istoricheskaya-geografiya-i-regionalistika-vzaimootnoshenie-vprotsesse-izucheniya-istoriko-kulturnyh-zon (дата обращения: 14.12.2020).

Губогло М.Н. И «пламень костра»...и пересадка сердца (Вместо предисловия к книге Е.Н. Квилинковой «Заговоры, магия и обереги в народной медицине гагаузов») // Квилинкова Е.Н. Заговоры, магия и обереги в народной медицине гагаузов. Кишинев: Elan Inc, 2010. C. 3-14.

Губогло М.Н. Магия песенного достояния гагаузов. Этнология в зеркале филологии (Вместо предисловия) // Квилинкова Е.Н. Гагаузский песенный фольклор - «Грамматика жизни». Кишинев: Elan Inc, 2011. С. 6-15.

Драгова Н.Н. Книга о гагаузских апокрифах - событие в европейской культурологи. Рец. Квилинкова Е.Н. Апокрифы в зеркале народной культуры гагаузов. Кишинев, 2012 // Stratum Plus. № 6. 2012. C. 359-361.

Квилинкова E.H. Апокрифы в зеркале народной культуры гагаузов. Кишинев; Благоевград: Tip. Centrală, 2012. 600 c.

Квилинкова Е.Н. Гагаузский народный календарь. Chişinău: Pontos, 2002. 184 c.

Квилинкова Е.Н. Гагаузский песенный фольклор - «Грамматика жизни». Кишинев: Elan Inc, 2011. 568 c.

Квилинкова Е.Н. Гагаузы в этнокультурном пространстве Молдовы (Народная культура и этническое самосознание гагаузов сквозь призму связи времен). Кишинев: Tipogr. Centrală, 2016. 732 с.

Квилинкова E.H. Гагаузы Молдовы и Болгарии (Сравнительное исследование календарной обрядности, терминов родства и фольклора). Chişinău: Pontos, 2005. 308 c.

Квилинкова E.Н. Заговоры, магия и обереги в народной медицине гагаузов. Кишинев: Elan Inc, $2010.390 \mathrm{c}$.

Квилинкова Е.Н. Культ волка у гагаузов сквозь призму этнокультурных символов. Кишинев: Tip. Centrală, 2014. 472 c.

Квилинкова Е.Н. Курбан у гагаузов (Архаическая современность). Кишинев: Tip. Centrală, 2015. $488 \mathrm{c}$. 
Квилинкова Е.Н. Методика и практика этнологических исследований (научно-методическое пособие). Кишинев: Tipogr. «Print Caro», 2020б. 224 с.

Квилинкова Е.Н. Православие - стержень гагаузской этничности. Комрат; София, 2013. Тір. Centrală, 2013. 872 c.

Квилинкова Е.Н. Соционормативная культура гагаузов: традиции и трансформации. Кишинев: Tipogr. «Print Caro», 2020a. 344 c.

Квилинкова Е.Н. Традиционная духовная культура гагаузов: этнорегиональные особенности. Кишинев: Business-Elita, 2007. 840 с.

Квилинкова Е.Н. Хаджылык у гагаузов как религиозный и этнокультурный феномен: от прошлого к настоящему. Кишинев: Tipogr. Centrală, 2017. 420 c.

Квилинкова E.Н. Этнорегиональный подход в изучении этнической истории гагаузов в контексте этно-регионалистики как нового научного направления в гагаузоведении // Наука. Образование. Культура. Сборник материалов Международной научно-практической конференции, посвященной 30-летию Комратского государственного университета. 11 февраля, 2021 г. Комрат: Изд-во Комратского Гос. Унив-та, 2021. С. 352-355.

Квилинкова Е.Н., Сакович В.А. Белорусы в Молдове и Молдова в белорусах. в серии «Мир глазами этнолога». Минск: Беларуская навука, 2021. 454 с.

Толстой Н.И. Проблема реконструкции древнеславянской духовной культуры // Язык и народная культура. Очерки по славянской мифологии и этнолингвистике. М., 1995. С. 41-60.

Sakovich, Vasily A.*

\section{Ethno-regional Studies as a New Area in Gagauz Studies (The Scientific Work of E.N. Kvilinkova - the Prominent Moldavian Ethnologist)}

\section{DOI: $10.33876 / 2311-0546 / 2021-4 / 309-324$}

The article is devoted to the new approaches and methods of studying the traditional spiritual culture and ethnic history of the Gagauz, developed by the prominent Moldavian ethnologist E.N. Kvilinkova. The author reveals the significance of the area of study she developed-ethnoregional studies - and the use of the term «regional». With her research, E.N. Kvilinkova proved that reconstructing the ethnic history of a small dispersed people is only possible by studying the general and the particular in it through the regional. That is, she has substantiated the need to study local ethnic groups in different regions. The present article summarizes the 30year experience of E.N. Kvilinkova at the Academy of Sciences of Moldova and examines the studies of the Gagauz spiritual culture that applied the ethno-regional approach. An analysis of the research results obtained in her published scientific articles and monographs revealed the scientific and practical significance of ethno-regionalism as a study area. Its use in Gagauz studies is even more valuable since the ethnogenesis of the Gagauz (Turkic-speaking and Orthodox) remains one of the most controversial topics to date. The article shows that E.N. Kvilinkova managed to study the ethnogenesis of the Gagauz people through the cultural genesis and fit the Gagauz culture into the niche of the Balkan Christian cultures. In this regard, the contribution of E.N. Kvilinkova as a scientist to Gagauz studies and ethnological science in general proves very significant.

Keywords: E.N. Kvilinkova, ethnology, ethno-regional studies, methods, Gagauz studies, ethnic history, ethnogenesis

For Citation: Sakovich, V.A. 2021. Ethno-regional Studies as a New Area in Gagauz Studies (The Scientific Work of E.N. Kvilinkova - the Prominent Moldavian Ethnologist). Herald of Anthropology (Vestnik Antropologii) 4: 309-324. 
Author Info: Sakovich, Vasily A. - Doctor of Political Science, Professor, Academy of Management under the President of the Republic of Belarus (Minsk, Republic of Belarus). E-mail: 113vs@mail.ru

\section{References}

Gerd, A.S. 2013. Istoricheskaya geografiya i regionalistika: vzaimootnoshenie v protsesse izucheniya istoriko-kulturnykh zon [Historical geography and regional studies: relationship in the process of studying historical and cultural zones]. Pskovskiy regionologicheskiy zhurnal, 107-116. Pskov. https://cyberleninka.ru/article/n/istoricheskaya-geografiya-i-regionalistika-vzaimootnoshenie-v-protsesse-izucheniya-istoriko-kulturnyh-zon (accessed 14.12.2020).

Guboglo, M.N. 2010. I «plamen kostra»... i peresadka serdtsa (Vmesto predisloviya k knige Ye. N. Kvilinkovoy «Zagovory, magiya i oberegi v narodnoy meditsine gagauzov») [And the "fire flame" ... and heart transplant (Instead of a preface to the book by E. N. Kvilinkova "Conspiracies, magic and amulets in the folk medicine of the Gagauz")]. Kvilinkova E.N. Zagovory, magiya i oberegi v narodnoy meditsine gagauzov, 3-14. Kishinev: Elan Inc.

Guboglo, M.N. 2011. Magiya pesennogo dostoyaniya gagauzov. Etnologiya v zerkale filologii (Vmesto predisloviya) [The magic of the song heritage of the Gagauz people. Ethnology in the mirror of philology (Instead of a preface)]. Kvilinkova E. N. Gagauzskiy pesennyy folklor"Grammatika zhizni», 6-15. Kishinev: Elan Inc.

Dragova, N.N. 2012. Kniga o gagauzskikh apokrifakh - sobytie v evropeyskoy kulturologi. Rets. Kvilinkova E.N. Apokrify v zerkale narodnoy kultury gagauzov. Kishinev, 2012 [The book about the Gagauz apocrypha is an event in European cultural studies. Retz. Kvilinkova E.N. Apocrypha in the mirror of the Gagauz folk culture. Chisinau, 2012]. Stratum Plus 6: 359-361.

Kvilinkova, E.N. 2012. Apokrify v zerkale narodnoy kultury gagauzov [Apocrypha in the mirror of the Gagauz folk culture]. Kishinev; Blagoevgrad: Tip. Centrală.

Kvilinkova, E.N. 2002. Gagauzskiy narodnyy kalendar [Gagauz folk calendar]. Chişinău: Pontos.

Kvilinkova, E.N. 2011. Gagauzskiy pesennyy folklor - «Grammatika zhizni» [Gagauz song folklore - "The grammar of life"]. Kishinev: Elan Inc.

Kvilinkova, E.N. 2016. Gagauzy v etnokulturnom prostranstve Moldovy (Narodnaya kultura i etnicheskoe samosoznanie gagauzov skvoz prizmu svyazi vremen) [Gagauz in the ethnocultural space of Moldova (Folk culture and ethnic identity of the Gagauz through the prism of the connection of times)]. Kishinev: Tipogr. Centrală.

Kvilinkova, E.N. 2005. Gagauzy Moldovy i Bolgarii (Sravnitelnoe issledovanie kalendarnoy obryadnosti, terminov rodstva i folklora) [Gagauzians of Moldova and Bulgaria (Comparative study of calendar rituals, terms of kinship and folklore)]. Chişinău: Pontos.

Kvilinkova, E.N. 2010. Zagovory, magiya i oberegi v narodnoy meditsine gagauzov [Conspiracies, magic and amulets in the folk medicine of the Gagauz people]. Kishinev: Elan Inc.

Kvilinkova, E.N. 2014. Kult volka u gagauzov skvoz prizmu etnokulturnykh simvolov [The cult of the wolf among the Gagauz people through the prism of ethnocultural symbols]. Kishinev: Tip. Centrală.

Kvilinkova, E.N. 2015. Kurban u gagauzov (Arkhaicheskaya sovremennost) [Kurban among the Gagauz (Archaic modernity)]. Kishinev: Tip. Centrală.

Kvilinkova, E.N. 2020b. Metodika i praktika etnologicheskikh issledovaniy (nauchno-metodicheskoe posobie) [Methodology and practice of ethnological research (scientific and methodological manual)]. Kishinev: Tipogr. «Print Caro».

Kvilinkova, E.N. 2013. Pravoslavie - sterzhen gagauzskoy etnichnosti [Orthodoxy is the core of the Gagauz ethnicity]. Komrat; Sofiya: Tip. Centrală.

Kvilinkova, E.N. 2020a. Sotsionormativnaya kultura gagauzov: traditsii i transformatsii [Socionormative culture of the Gagauz people: traditions and transformations]. Kishinev: Tipogr. «Print Caro». 
Kvilinkova, E.N. 2007. Traditsionnaya dukhovnaya kultura gagauzov: etnoregionalnye osobennosti [Traditional spiritual culture of the Gagauz people: ethnoregional features]. Kishinev: Business-Elita. Kvilinkova, E.N. 2017. Khadzhylyk u gagauzov kak religioznyy $i$ etnokulturnyy fenomen: ot proshlogo k nastoyashchemu [Hajylyk among the Gagauz people as a religious and ethnocultural phenomenon: from the past to the present]. Kishinev: Tipogr. Centrală.

Kvilinkova, E.N. 2021. Etnoregionalnyy podkhod v izuchenii etnicheskoy istorii gagauzov v kontekste etno-regionalistiki kak novogo nauchnogo napravleniya $\mathrm{v}$ gagauzovedenii [Ethno-regional approach to the study of the ethnic history of the Gagauz people in the context of ethno-regionalism as a new scientific direction in Gagauz studies]. Nauka. Obrazovanie. Kultura. Sbornik materialov Mezhdunarodnoy nauchno-prakticheskoy konferentsii, posvyashchennoy 30-letiyu Komratskogo gosudarstvennogo universiteta. 11 fevralya, 2021 g.: 352-355. Komrat.

Kvilinkova, E.N., Sakovich, V.A. 2021. Belorusy v Moldove i Moldova v Belorusah [Belarusians in Moldova and Moldova in Belarusians]. V serii «Mir glazami etnologa». Minsk: Belaruskaya navuka.

Tolstoy, N.I. 1995. Problema rekonstruktsii drevneslavyanskoy dukhovnoy kultury [The problem of reconstruction of ancient Slavic spiritual culture]. Yazyk i narodnaya kultura. Ocherki po slavyanskoy mifologii i etnolingvistike: 41-60. Moscow. 